\title{
Percepções e Escolhas de Adolescentes sobre Saúde no Contexto da Residência Multiprofissional
}

\author{
Débora Silveira Duarte ${ }^{1}$ \\ ${ }^{1}$ Psicóloga, MG, Brasil. \\ Lilian Fernanda Silva ${ }^{2}$ \\ ${ }^{2}$ Assistente social, MG, Brasil.
}

\author{
Virgínia Junqueira Oliveira ${ }^{3}$ \\ ${ }^{3}$ Universidade Federal de São João del-Rei, MG, Brasil. \\ Patrícia Pinto Braga ${ }^{3}$ \\ ${ }^{3}$ Universidade Federal de São João del-Rei, MG, Brasil.
}

\begin{abstract}
Resumo: Este artigo é um recorte de um projeto maior intitulado "O empoderamento do/da adolescente para a promoção da sua saúde no contexto de uma residência multiprofissional". Trata-se de um estudo exploratório e interpretativo de abordagem qualitativa realizado em uma escola pública estadual no contexto de uma Residência Multiprofissional em Saúde do Adolescente em um município de Minas Gerais. O objetivo foi identificar as percepções e escolhas dos(as) adolescentes em relação a sua saúde. Como técnica de coleta de dados, utilizaram-se oficinas com estudantes do Ensino Médio. Os dados foram transcritos na íntegra, submetidos à análise temática e interpretados a partir do referencial teórico da psicologia social. A análise permitiu identificar diferentes temas, organizados em três categorias: "concepções de adolescentes sobre saúde", atreladas sobremaneira ao paradigma biomédico e à corrente moderna de promoção da saúde; "influências nas escolhas e na saúde dos(as) adolescentes", que destacam o papel da família e das relações interpessoais; "Onde os/as adolescentes buscam saúde", que evidencia a internet como lócus primário da busca por informações. As categorias foram discutidas em três eixos: "adolescências, saúde e seus corpos: rascunho ou potência?", "adolescências, influências, escolhas e saúde" e "adolescências, cultura digital e saúde: articulações possíveis". Conclui-se que, para promover saúde durante a adolescência, é preciso despir-se de concepções generalistas e dos ideais de adolescência, extrapolar os espaços tradicionais de cuidado com esse público e considerar profundamente os determinantes sociais em saúde.
\end{abstract}

Palavras-chave: Adolescência, Escolhas, Promoção da saúde.

\section{Health Perceptions and Choices of Adolescents in a Multidisciplinary Residency Context}

\begin{abstract}
This paper is an excerpt from a larger project entitled "O Empoderamento do/da Adolescente para a Promoção da sua Saúde no Contexto de uma Residência Multiprofissional" (Empowerment of Adolescents to Promote Health in a Multidisciplinary Context). This is an exploratory and explanatory qualitative study conducted in a public school from a municipality of Minas Gerais, in the context of a Multidisciplinary Residency in Adolescent Health, whose aim was to identify adolescents' perceptions and choices concerning health. Data were collected by means of workshops conducted with High School students, fully transcribed, analyzed according to theme, and interpreted from the theoretical perspective of Social Psychology. Data analysis identified the presence of multiple themes, which were divided into three categories: 'Adolescents' perception on health', associated with the biomedical paradigm as well as to Modern Health Promotion; 'Influences on adolescents' choices and health', which highlights the role of family and interpersonal relationships; and 'Means
\end{abstract}


through which adolescents look for information', which indicates the Internet as a basic locus for information search. These categories were approached from three axes: 'Adolescences, health, and their bodies: drafts or power?'; 'Adolescences, influences, choices, and health'; and 'Adolescences, digital culture, and health: possible articulations'. The results indicate that promoting health among adolescents requires us to break with generic and idealist concepts underlying adolescence, extrapolate the traditional spaces of healthcare aimed at this public, and consider the Social Determinants of Health.

Keywords: Adolescence, Choices, Health promotion.

\title{
Percepciones y Elecciones de Adolescentes sobre Salud en el Contexto de la Residencia Multiprofesional
}

\begin{abstract}
Resumen: Este artículo presenta un recorte de un proyecto más amplio, "O Empoderamento do/ da Adolescente para a Promoção da sua Saúde no Contexto de uma Residência Multiprofissional” ("El empoderamiento del/la Adolescente en la Promoción de la Salud en el Contexto de una Residencia Multiprofesional”). Este es un estudio exploratorio e interpretativo, de metodología cualitativa, realizado en una escuela pública de la red estatal, en el contexto de una Residencia Multiprofesional en Salud del Adolescente, en un municipio de Minas Gerais, Brasil. Su objetivo es analizar las percepciones y elecciones de los/las adolescentes con relación a la salud. La técnica de recolección de datos se basó en la realización de talleres a los cuales acudieron a estudiantes de la secundaria. Los datos obtenidos fueron transcriptos en su totalidad, sometidos a un análisis temático e interpretados desde la psicología social. Este análisis permitió organizar los diferentes temas identificados según tres categorías: "Concepciones de adolescentes sobre la salud", que está vinculada al paradigma biomédico y a la corriente moderna de la promoción de la salud; "Influencias en las elecciones y en la salud de los/las adolescentes", que resalta el rol de la familia y de las relaciones interpersonales; y "Dónde los/las adolescentes buscan salud", que señala que internet es el locus primario para la búsqueda de informaciones. Son tres los ejes que orientan la discusión de dichas categorías: "Adolescencias, salud y sus cuerpos: ¿borrador o potencia?", "Adolescencias, influencias, elecciones y salud"; y "Adolescencias, cultura digital y salud: articulaciones posibles". Se concluye que, para la promoción de la salud en las adolescencias, es necesario romper con concepciones generalistas e idealistas acerca de la adolescencia, ir más allá de los espacios tradicionales de atención a este público y tener en cuenta, sobre todo, los determinantes sociales en salud.
\end{abstract}

Palabras clave: Adolescencia, Elecciones, Promoción de salud.

\section{Introdução}

Ao longo da história, diferentes paradigmas de saúde foram (re)construídos. No paradigma biomédico da saúde, esta é compreendida como ausência de doenças e pensada como um fenômeno biológico, individual e unicausal. Duras críticas são feitas a esse paradigma, marcadamente reducionista e centrado na doença, de forma que, a partir da década de 1940, quando a Organização Mundial de Saúde (OMS) propôs uma definição ampliada de saúde como o completo bem-estar físico, psíquico e social, começa-se a considerar as múltiplas necessidades sociais que envolvem a perspectiva da saúde (Puttini, Pereira Junior, \& Oliveira, 2010).

A "corrente moderna de promoção de saúde", embora incorpore o conceito ampliado de saúde, ainda enfatiza a ação individual, adotando uma perspectiva comportamental, e responsabiliza os indivíduos por seus problemas de saúde, sendo ainda bastante influenciada pelo paradigma biomédico. Já a "nova 
promoção da saúde", cujos primórdios estão atrelados à Conferência de Alma-Ata, ocorrida em 1981, compreende a saúde como produção social, levando em conta uma perspectiva contextual, histórica, coletiva e ampliada (Cavalcanti, Lucena, \& Lucena, 2015), passando a considerar e a fortalecer cada vez mais a discussão dos Determinantes Sociais de Saúde (DSS), definidos como as "condições sociais em que as pessoas nascem, crescem, vivem, trabalham e envelhecem” (Organização Mundial de Saúde [OMS], 2011).

No Brasil, a institucionalização da promoção da saúde iniciou-se após a promulgação da Constituição Federal de 1988 e, desde então, ações são implementadas de forma intersetorial. Mas a Política Nacional de Promoção da Saúde (PNPS) foi aprovada somente em março de 2006, por meio da Portaria n. 687 (Ministério da Saúde, 2006). A seguir, relata-se a proposta da PNPS feita pelo Ministério da Saúde (MS):

A PNPS traz em sua base o conceito ampliado de saúde e o referencial teórico da promoção da saúde como um conjunto de estratégias e formas de produzir saúde, no âmbito individual e coletivo, caracterizando-se pela articulação e cooperação intra e intersetorial, pela formação da Rede de Atenção à Saúde (RAS), buscando articular suas ações com as demais redes de proteção social, com ampla participação e controle social (Ministério da Saúde, 2018, p. 25).

Com o objetivo de melhorar as condições e as formas de viver, promover equidade e reduzir as vulnerabilidades e os riscos à saúde, a PNPS atua em oito eixos prioritários, sendo eles: a) formação e educação permanente; b) alimentação adequada e saudável; c) práticas corporais e atividades físicas; d) enfrentamento ao uso do tabaco e de seus derivados; e) enfrentamento do uso abusivo de álcool e de outras drogas; f) promoção da mobilidade segura; g) promoção da cultura da paz e dos direitos humanos; h) promoção do desenvolvimento sustentável (Ministério da Saúde, 2018).

\section{Promoção da saúde no contexto das adolescências}

Conforme estabelecem a OMS e o MS, considera-se adolescência o período entre os 10 e 19 anos (MS, 2010). Além disso, em conformidade com o Estatuto da Criança e do Adolescente (ECA) (Lei n. 8.069, 1990), reconhecem-se crianças e adolescentes como sujeitos de direito, com prioridade absoluta nas políticas públicas do país (Ministério da Saúde, 2010, 2017).

O período da adolescência pode ser definido como uma etapa do desenvolvimento marcada por intensas modificações físicas, cognitivas e socioemocionais (Macedo, Petersen, \& Koller, 2017). As transformações vivenciadas por cada adolescente são atravessadas pela cultura, pela sociedade e pelo tempo histórico em que o(a) adolescente se insere, o que torna mais apropriado falar em adolescências, no plural, pois não é um mero detalhe considerar questões de gênero, classe social, costumes, crenças religiosas, etnia, região geográfica, dentre outras especificidades (Guareschi, 2012; Le Breton, 2017; Ministério da Saúde, 2010; Souza \& Silva, 2018).

Diante das mudanças vividas, as relações nas adolescências são reconfiguradas, as relações com o grupo de pares começam a ganhar destaque e a aceitação social será essencial para o desenvolvimento saudável dos(as) adolescentes (Veppo, Perpétuo, Ribeiro, \& Veríssimo, 2020). A família fica em segundo plano, o que não diminui a importância do vínculo familiar de qualidade para a saúde do(a) adolescente (Prioste, Tavares, \& Magalhães, 2019; Ribeiro \& Rocha, 2017; Rozemberg, Avanci, Schenker, \& Pires, 2014). A família também terá papel importante na prevenção de comportamentos de risco, como o uso/abuso de drogas por adolescentes (Reis, Malta, \& Furtado, 2018), problema de saúde crescente entre esse grupo (Ribeiro et al., 2018).

As transformações biopsicossociais do(a) adolescente suscitam variados sentimentos (Macedo et al., 2017) e a mídia terá um papel significativo na construção de sua autopercepção e no cuidado com sua saúde (Bertolini, 2016; Bittar \& Soares, 2020; Le Breton, 2003; Marques et al., 2016). Isso também é válido para o ciberespaço, que atravessará a construção da identidade dos(as) adolescentes, bem como seus cuidados e discursos relacionados à saúde (Alves, 2017; Bialer \& Voltolini, 2017; Moretti, Silva, \& Barsottini, 2016; Tiburi, 2016), de forma que se apresenta como alternativa interessante para a construção de ações de promoção da saúde nesse grupo (Oliveira, Gessner, Souza, \& Fonseca, 2016).

Outro ponto central das transformações nas adolescências e importante eixo para o cuidado com a saúde de adolescentes é a sexualidade, também pensada como uma construção sociocultural (Campos, 
Paiva, Mourthé, Ferreira, \& Fonseca, 2017) e compreendida como um "aspecto central do ser humano ao longo de toda sua vida, e nela estão circunscritos elementos relativos ao sexo, às identidades e aos papéis de gênero, à orientação sexual, ao prazer, à intimidade e à reprodução" (Organização Pan-Americana de Saúde [Opas] \& Ministério da Saúde, 2017).

Sabe-se que, majoritariamente, adolescentes costumam buscar os serviços de saúde em situações de agravos à saúde, como quando apresentam problemas clínicos ou precisam de alguma intervenção pontual, recorrendo principalmente ao profissional médico (Brito \& Rocha, 2019; Silva, Matsukura, Ferigato, \& Cid, 2019; Vinagre \& Barros, 2019). Além disso, a literatura aponta tendências de autorresponsabilização pelo próprio bem-estar e saúde, sem considerar os DSS (Passos, Gugelmin, Castro, \& Carvalho, 2013; Sennett, 1999).

O Brasil se encontra entre os países com os mais altos índices de desigualdade social do mundo (Oxford Committee for Famine Relief [Oxfam], 2016). Nesse sentido, quando se considera o contexto de desigualdade no qual os(as) adolescentes do Brasil estão inseridos, é preciso reconhecer que os DSS mostram-se como um importante desafio e que os fatores que condicionam as iniquidades em saúde e as necessidades dos grupos afetados pela pobreza e pela desvantagem social não podem ser menosprezados (Dimenstein, Siqueira, Macedo, Leite, \& Dantas, 2017; Ministério da Saúde, 2018).

\section{Nosso ponto de partida}

Parte-se de um contexto de atuação de residentes nos campos de prática de um Programa de Residência Multiprofissional em Saúde do Adolescente (Remsa) de uma instituição de ensino superior no estado de Minas Gerais. A atuação da equipe multiprofissional, composta por seis categorias profissionais - psicologia, enfermagem, nutrição, odontologia, serviço social e fisioterapia -, ocorre em uma Unidade Básica de Saúde (UBS) em seu território de abrangência. As ações desenvolvidas envolvem tratamento, promoção e prevenção de caráter uni e multiprofissional, e têm como público-alvo adolescentes entre 10 e 19 anos.

Foi proposto o desenvolvimento de um amplo projeto de pesquisa pelas residentes, de caráter quali-quantitativo, intitulado "O empoderamento do/da adolescente para a promoção da sua saúde no contexto de uma residência multiprofissional". Assim, o artigo aqui apresentado é um recorte dessa pesquisa mais ampla desenvolvida pelas residentes.

As questões que nortearam a pesquisa deste artigo foram: "O que os(as) adolescentes entendem por saúde?" e "Como os(as) adolescentes têm feito suas escolhas em relação a sua saúde?” Partindo dessas perguntas, o objetivo foi identificar as percepções e escolhas dos(as) adolescentes em relação a sua saúde. A relevância desta pesquisa encontra-se na possibilidade de evidenciar a compreensão e as reais demandas dos(as) adolescentes participantes acerca da promoção de sua saúde. As respostas às questões levantadas permitem a elaboração de novas perguntas de pesquisa e sinalizam para estratégias de cuidados que podem ser direcionadas a esse público.

\section{Método}

Trata-se de uma pesquisa qualitativa de caráter exploratório e interpretativo. Participaram dessa etapa do estudo adolescentes que estavam matriculados no Ensino Médio de uma escola pública estadual da área de abrangência da UBS de atuação das residentes.

Utilizou-se a oficina como método de coleta de dados, por se tratar de uma metodologia ativa, na qual a construção do conhecimento pode ocorrer de forma conjunta, envolvendo os sujeitos de maneira integral e facilitando o processo de compreensão de suas formas de agir, pensar e sentir (Afonso, 2006). As oficinas se apresentam como uma prática discursiva, ou seja, como um espaço de negociação e produção coletiva dos sentidos que torna possível visualizar, construir e reconsiderar as versões da realidade (Spink, Menegon, \& Medrado, 2014).

Para a seleção dos(as) participantes, utilizou-se a técnica snowball sampling (bola de neve), que consiste em uma amostra não probabilística que usa cadeias de referência e que permite alcançar grupos de difícil acesso (Vinuto, 2014). Empregando essa técnica, realizou-se o sorteio de três estudantes, um de cada ano do Ensino Médio $\left(1^{\circ}, 2^{\circ}\right.$ e $3^{\circ}$ anos). Cada um deles indicou outro(a) adolescente de seu ano, que indicou outro(a) estudante, até somarem 10 participantes.

Foram realizadas duas oficinas. Embora tenham sido convidados 10 adolescentes e tenha sido pactuado previamente o dia dos encontros com eles(as), sete efetivamente compareceram à primeira oficina e, à segunda, seis. A Tabela 1 descreve os participantes de ambas as oficinas, atribuindo-lhes um código que será utilizado posteriormente na apresentação dos dados. 
Tabela 1

Caracterização dos(as) adolescentes participantes.

\begin{tabular}{ccccc}
\hline Código & Idade & Gênero & $\begin{array}{c}\text { Participou } \\
\text { da Oficina } \\
1\end{array}$ & $\begin{array}{c}\text { Participou } \\
\text { da Oficina } \\
2\end{array}$ \\
\hline A1 & 16 & Feminino & Sim & Sim \\
A2 & 19 & Masculino & Sim & Sim \\
A3 & 18 & Masculino & Não & Sim \\
A4 & 16 & Feminino & Sim & Sim \\
A5 & 17 & Masculino & Sim & Sim \\
A6 & 16 & Feminino & Sim & Sim \\
A7 & 15 & Feminino & Sim & Não \\
A8 & 17 & Não & Sim & Não \\
\hline
\end{tabular}

Todos(as) participantes relataram residir na região sudoeste do município no qual foi realizada a pesquisa, mesma região onde a escola-cenário está situada. Essa escola oferece o Ensino Fundamental II e o Ensino Médio e tem cerca de 900 alunos de toda a cidade, o que a caracteriza como uma das maiores escolas do município. É uma escola-cenário de diversas pesquisas de instituições de ensino superior e, há dois anos, é alvo de ações e atendimentos frequentes da Remsa.

Para o desenvolvimento das oficinas, foi realizado um pré-encontro com os(as) adolescentes, no qual foi apresentada a pesquisa e pactuados o contrato de convivência e os dias em que os encontros seriam realizados. Também se recolheram os Termos de Consentimento Livre e Esclarecido (TCLE), assinados pelos(as) pais/responsáveis dos adolescentes, e os Termos de Assentimento Livre e Esclarecido (Tale), assinados pelos adolescentes. Posteriormente, foram realizados três encontros, com roteiros elaborados pelas pesquisadoras, sendo considerados para este trabalho apenas os encontros 1 e 2, descritos na Tabela 2 .

Tabela 2

Organização das oficinas.

\begin{tabular}{|c|c|c|c|}
\hline Tema & Objetivos & Organização das oficinas & Perguntas norteadoras \\
\hline $\begin{array}{l}1^{\circ} \text { Encontro: } \\
\text { Escolhas }\end{array}$ & $\begin{array}{l}\text { - Compreender se os(as) } \\
\text { adolescentes têm feito } \\
\text { escolhas; } \\
\text { - Compreender como } \\
\text { os(as) adolescentes fazem } \\
\text { suas escolhas. }\end{array}$ & $\begin{array}{l}1^{\circ} \text { momento: apresentação e } \\
\text { integração. } \\
2^{\circ} \text { momento: exibição e } \\
\text { debate do curta-metragem } \\
\text { La Luna e construção de } \\
\text { cartaz individual sobre } \\
\text { escolhas; apresentação do } \\
\text { cartaz e discussão a partir das } \\
\text { perguntas norteadoras. } \\
3^{\circ} \text { momento: encerramento. }\end{array}$ & $\begin{array}{l}\text { - O que os(as) adolescentes } \\
\text { entendem por escolha? } \\
\text { - Como os(as) adolescentes } \\
\text { fazem suas escolhas? } \\
\text { - O que influencia as escolhas } \\
\text { dos(as) adolescentes? }\end{array}$ \\
\hline $\begin{array}{l}2^{\circ} \text { Encontro: } \\
\text { Saúde }\end{array}$ & $\begin{array}{l}\text { - Compreender as } \\
\text { percepções dos(as) } \\
\text { adolescentes sobre saúde; } \\
\text { - Compreender como } \\
\text { os(as) adolescentes } \\
\text { fazem suas escolhas } \\
\text { relacionadas à saúde. }\end{array}$ & $\begin{array}{l}1^{\circ} \text { momento: integração. } \\
2^{\circ} \text { momento: construção de } \\
\text { colagem coletiva sobre saúde; } \\
\text { apresentação da colagem } \\
\text { e discussão a partir das } \\
\text { perguntas norteadoras. } \\
3^{\circ} \text { momento: encerramento. }\end{array}$ & $\begin{array}{l}\text { - O que os(as) adolescentes } \\
\text { entendem por saúde? } \\
\text { - Como os(as) adolescentes } \\
\text { fazem escolhas em relação a } \\
\text { sua saúde? } \\
\text { - O que influencia os(as) } \\
\text { adolescentes ao fazerem } \\
\text { escolhas em relação a sua saúde? }\end{array}$ \\
\hline
\end{tabular}

Os encontros duraram cerca de 60 minutos e foram conduzidos por duas pesquisadoras/residentes, enquanto duas outras registravam suas observações. Os(as) participantes foram dispostos em semicírculo, em cadeiras numeradas para facilitar os registros das observadoras. Para garantir o registro do conteúdo discutido nos encontros, foram usados dois gravadores de áudio, posicionados em pontos estratégicos. Ao término, o conteúdo dos áudios foi transcrito na íntegra.

Os materiais utilizados para análise foram as transcrições dos dois encontros das oficinas, os cartazes e as colagens produzidos, além das observações realizadas. Para garantir o sigilo dos participantes, o material analisado foi codificado conforme a Tabela 3 . 


\section{Tabela 3}

Codificação do material analisado.

\begin{tabular}{|c|c|}
\hline 'O(no $\left.\mathrm{n}^{\circ}\right) \mathrm{A}\left(\mathrm{n}^{0}\right)^{\prime}$ & $\begin{array}{l}\text { Fala de um participante, na qual } \mathrm{O} \text { (oficina) vem seguido do número } 1 \text { ou } 2 \text {, correspondente } \\
\text { à oficina em que o dado foi gerado, e A (adolescente) vem seguido de número entre } 1 \text { e } 8 \text {, } \\
\text { correspondente ao número atribuído a cada adolescente. }\end{array}$ \\
\hline $\mathrm{CC}\left(\mathrm{n}^{0}\right)$ & $\begin{array}{l}\text { Cartaz coletivo produzido, seguido do número } 1 \text { ou } 2 \text {, correspondente ao encontro no qual } \\
\text { foi produzido. }\end{array}$ \\
\hline $\operatorname{CIA}\left(\mathrm{n}^{0}\right)$ & $\begin{array}{l}\text { Cartaz individual produzido, seguido de A (adolescente), juntamente com número entre } 1 \text { e } 8 \text {, } \\
\text { correspondente ao participante que o produziu. }\end{array}$ \\
\hline 'FCCA $\left(n^{o}\right)^{\prime}$ & $\begin{array}{l}\text { Fala referente a cartaz coletivo produzido na Oficina } 2 \text {, seguido de } \mathrm{A} \text { (adolescente), juntamente } \\
\text { com número entre } 1 \text { e } 8 \text {, correspondente ao número atribuído a cada adolescente. }\end{array}$ \\
\hline $\operatorname{FCIA}\left(\mathrm{n}^{\circ}\right)$ & $\begin{array}{l}\text { Fala referente a cartaz individual produzido na Oficina 1, seguido de A (adolescente), juntamente } \\
\text { com número entre } 1 \text { e } 8 \text {, correspondente ao número atribuído a cada adolescente. }\end{array}$ \\
\hline $\mathrm{O}\left(\mathrm{n}^{\mathrm{o}}\right)$ & Observações realizadas seguidas do número 1 ou 2 , correspondente ao observador-autor. \\
\hline
\end{tabular}

Para identificar o conteúdo latente dos significados apresentados, todo o material foi submetido à análise temática de conteúdo, conforme Minayo e Gomes (2009), que consiste em localizar os núcleos de sentido que faziam parte da comunicação e que, por sua frequência ou presença, puderam ajudar a revelar o objetivo analítico.

As etapas da análise consistiram em leitura exaustiva do material; decomposição em partes para identificação dos temas, que foram agrupados em categorias; e interpretação dos dados obtidos a partir de autores e pesquisas que discutissem as adolescências e a promoção da saúde, além de outros autores que nos auxiliassem na compreensão dos "não ditos" nas oficinas segundo uma perspectiva da psicologia social.

A psicologia social é uma área da psicologia que se preocupa em estudar o comportamento humano naquilo em que ele é socialmente influenciado, partindo do pressuposto de que o homem é produto e produtor da história, não sendo possível a compreensão dele de maneira isolada do contexto sócio-histórico-cultural no qual vive (Lane, 2006).

Todos os cuidados éticos foram tomados, conforme os termos da Resolução do Ministério da Saúde n. 466, de 12 de dezembro de 2012. O estudo foi submetido ao Comitê de Ética em Pesquisa Envolvendo Seres Humanos (Cepes) da Universidade Federal de São João del-Rei, Campus Centro-Oeste, e aprovado em 28 de março de 2018 pelo parecer consubstanciado n. 2.570.687.

\section{Resultados}

A análise temática permitiu identificar nos discursos dos(as) adolescentes diferentes temas, que, agrupados, formaram as três categorias apresentadas a seguir.

A primeira categoria diz respeito às "concepções de adolescentes sobre saúde” e apresentou os conteúdos que faziam referência ao que fosse considerado como saúde pelos(as) adolescentes. Segundo observado, "ao longo do encontro [2], percebe-se que a ideia central de saúde para os(as) participantes é a ideia de alimentação regrada e prática de atividades físicas. Mesmo quando trazem outros aspectos, associam, de forma indireta, saúde a essa perspectiva" (O1).

No discurso apresentado pelos participantes, a concepção de saúde está associada à alimentação regrada e à prática de atividade física, que pode ser percebida, entre outras, nesta fala: "Hummm ..., acho que [saúde] é fazer atividade fisica, comer bem, acho que é só isso" (O2A7). Pode ser observada também nesta: “. . . Vamo comer chocolate? Vamo! Mas também não é só comer besteira. Vamo tá regrando essas coisas, porque, se come só besteira, sua saúde não vai tá legal. Então, você tem que tá sempre controlando isso. Fazer exercício físico" (O2A3). Essa concepção também fica evidenciada no cartaz produzido, no qual foram identificadas 11 imagens que faziam referência à saúde como alimentação ou como prática de atividade física. A Figura 1 contém algumas dessas imagens, que foram digitalizadas.

Um dos adolescentes tomou a frente na apresentação do cartaz e, ao explicá-lo, enunciou algumas falas que convergem com essa primeira forma de entender saúde, como demonstra o seguinte trecho de fala: "Aí, por exemplo aqui, [apontando para imagens referentes à alimentação], seria alimentação, como aqui também. Ali e aqui, também seria alimentação. Então, saúde também é se alimentar bem, além dos esportes" (FCCA3). Isso é observado também nesta fala: 


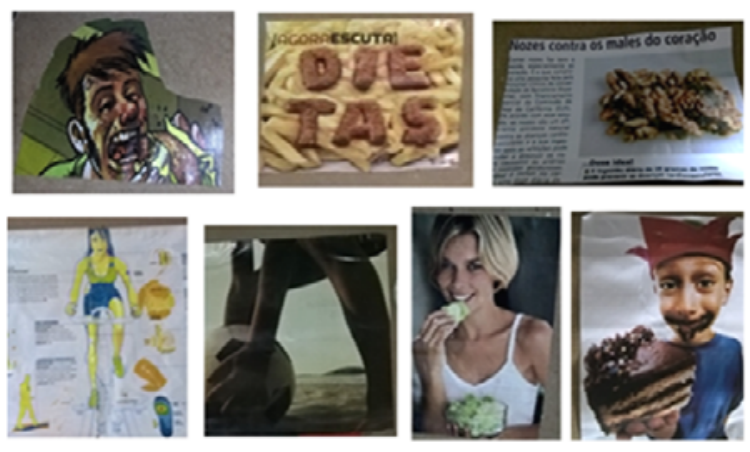

Figura 1

Algumas colagens feitas em cartaz construído coletivamente que representam as percepções sobre saúde dos(as) adolescentes participantes da pesquisa.

O que que vocês concordam que seria isso aqui? [apontando para imagens de atividade física] Tipo esporte, né? Fazer atividade física. Todo mundo concorda que isso, isso aqui, seria atividade física, né? É um moço na esteira, no caso. E aqui tem algumas outras atividades (FCCA3).

Outra forma de pensar saúde apresentada pelos(as) adolescentes foi a associação dela à ausência de doenças, exemplificada nas falas "saúde seria, tipo, ser uma pessoa saudável” (O2A3) e "[Saúde é] ela [a pessoa] tá [se] sentindo bem, é ela tá com saúde" (O2A2).

Os(as) participantes também associaram saúde à funcionalidade, conforme pode ser observado na fala "É... também nosso corpo tá funcionando bem. Às vezes, a gente tá assim, bem, mas tá acontecendo alguma coisa de errado, né??" (O2A1), bem como na fala "Pra mim, é isso também, que ... tudo tá funcionando do jeito que tem que funcionar.... Nada de errado" (O2A4).

Os(as) adolescentes também entendem que saúde é algo de responsabilidade exclusiva deles(as). Quando perguntamos a quem atribuem a responsabilidade por sua saúde, de forma unânime consideraram que a atribuíam a eles próprios: “Eu mesmo/ mesma" (O2A1, O2A2, O2A3, O2A4, O2A5, \& O2A7).

Outra construção identificada no discurso dos(as) adolescentes foi a de saúde associada à felicidade e ao bem-estar, representada nas seguintes falas: "[Saúde é] bem-estar, deixar de lado a opinião dos outros e pensar mais em felicidade" (O2A7); "[Saúde é] bem-estar consigo mesmo" (O2A2).

Para um dos adolescentes participantes, a saúde está associada à prevenção de infecções sexualmente transmissíveis (IST): "Isso aqui seria uma camisinha, né? Seria prevenção. Porque você não tendo uma camisinha, você poderia ter uma doença sexualmente transmissivel. Então, você não teria saúde" (FCCA3).

Por fim, o material analisado também permitiu identificar que, para um dos adolescentes participantes, a saúde está associada ao resultado de muito esforço e sacrifícios. Conforme poderá ser observado na fala, o uso do gerúndio retrata o movimento, a busca e as exigências do cotidiano para alcançar uma vida saudável:

Não digo que seria assim ruim, mas é um sacrificio a mais, por exemplo, enquanto tá uma pessoa ali,é, saíno, uma pessoa ali bebeno, uma pessoa fazeno isso e tal, você tá aí, fazendo a sua dieta, você tá gastando o seu tempo, o seu dinheiro . . f fazendo um tanto de coisa, sendo que as outras pessoas não faz. Ocê parece que vê as pessoas e fala que elas estão mais felizes que você! ... Ocê faz o sacrificio, mas, no final, cêvai ter o resultado. Eu acho queé isso(O2A3).

A segunda categoria informou as "influências nas escolhas e na saúde dos(as) adolescentes”, apresentando aquilo que os(as) adolescentes consideraram influenciar suas escolhas, também relativas à saúde. A análise dos dados mostrou que, ao fazerem escolhas, os(as) adolescentes costumam ser influenciados(as) por seus familiares, especialmente pela figura materna, seja no sentido de atribuição das escolhas, conforme pode ser observado nas falas "Quando estou indecisa, deixo minha mãe decidir" (O1A4), "[Quando não consigo decidir], peço ajuda para minha mãe" (O1A6), seja no sentido de limitação delas, de acordo com a fala "Os pais às vezes não deixam a gente escolher como quer" (O1A2), bem como na descrição “Meus pais quase nunca respeitam quando escolho. Algumas, eles apoiam. Algumas, não. Outras, eles odeiam" (CIA8).

Também foi possível observar influências familiares nos hábitos alimentares, conforme aponta uma das adolescentes entrevistadas: "Lá em casa, a gente passa até quatro anos sem comer um hambúrguer. Pra falar a verdade, então, acho que isso influencia muito na minha vida, porque, se não fosse isso, não sei" (O2A7). Isso também é observado na prática ou não de atividades físicas: "Acho que a criação influencia muito. Se, desde pequena, minha mãe incentiva a praticar um esporte, uma natação ou andar de bicicleta, eu vou crescer com aquilo. Agora, se ela não faz também, é muito difícil eu criar interesse" (O2A2). 
As relações interpessoais também se apresentam como um fator que influencia as escolhas, como relata uma das adolescentes: "Eu gosto de observar a vida das pessoas próximas e analisar as escolhas delas. $E$, então, talvez a influência de tal pessoa seja o que eu vou seguir" (FCIA2). Outra adolescente diz: "Também, às vezes, influencia no fato de se importar com o que as pessoas vão pensar" (O1A1).

$\mathrm{Na}$ fala a seguir, é possível perceber as influências das relações interpessoais na saúde: "Não se socializar ou evitar contato com outras pessoas pode deixá-lo triste elou com a sensação de se sentir solitário, ou entediado. E, para passar o tédio, algumas pessoas comem apenas para se aliviar dessa sensação" (O2A4). Uma das participantes, em sua fala, ainda aponta como os desdobramentos das relações interpessoais podem afetar sua saúde, destacando como um aspecto "social" pode influenciar a "saúde mental" e, consequentemente, a "saúde física”:

Às vezes, você ser um pouco diferente, as pessoas meio que te excluem, acaba te deixando de lado. Aí, isso influencia na saúde mental. Aí, no caso da saúde mental, você vai ficar entediada, vai ficando chateada, o que te influencia na saúde física. E é isso ... vai afetando (O2A1).

No que concerne ao debate dos(as) adolescentes sobre uso e abuso de substâncias, há apontamentos de influências positivas na saúde quando são utilizadas em tratamentos de saúde; porém, concluem que essas substâncias têm influências negativas. Seja a droga lícita, seja a ilícita, o excesso em seu uso é um problema para a saúde. Vejamos o debate a seguir:

Eu não sei se maconha faz bem à saúde ... eu acho que não (O2A5). Deve ser maconha como vício, $n e ́ ?(\mathrm{O} 2 \mathrm{~A} 4)$. Acho que a maconha em si, assim, ela não é ruim, porque, se você for ver, ela pode até ser usada como medicamento, mas o uso muito elevado dela pode causar o vício. Aí, faz mal. Então, a maconha não, mas o uso excessivo dela pra usar como droga. . . . Não é bom usar drogas. Drogas nenhuma! (O2A3) (Diálogo entre O2A5, O2A4 e O2A3).

Uma das narrativas aponta o excesso de trabalho como um fator determinante que contribui para a deterioração da saúde, podendo gerar agravos à saúde mental. Um dos adolescentes, ao identificar a imagem de notas de dólares no CC2, sinaliza:

E aqui, eu acho, seria dinheiro, né? ... Por exemplo, dinheiro é bom? É. Mas a gente tem que pensar em comprar as nossas necessidades, porque, se a gente for ficar, tipo assim, 'Ai, eu tenho que trabalhar mais toda vez pra ganhar mais dinheiro', a gente acaba ficando com problema, tipo assim, mental ... Tipo assim, a gente acaba ficando transtornado (FCCA4).

A religião também aparece como influência nas escolhas realizadas, como foi possível constatar na seguinte fala: "Eu acho que a religião [influencia] ... Ah . . não sei . . Julgam o que é certo ou não, e você ter que precisar respeitar" (O1A5). Um dos adolescentes também postula que a religião se apresenta como uma influência positiva na saúde, por considerá-la como um suporte. Ao identificar a imagem de uma cruz no CC2, nos sinaliza:

... Aqui, eu coloquei isso aqui, seria religião, né ... A gente sempre tem que ter uma religião, uma coisa pra seguir. Porque, é como se ... como se diz. É como se, hoje em dia, o mundo fosse . . vamo falar assim, uma corrente muito forte, e a religião seria uma coisa [em] que a gente poder se segurar, [em] que a gente pode confiar (FCCA3).

Um dos adolescentes apontou que, ao fazer escolhas sobre a saúde, ele pode pautá-las em questões estéticas influenciadas pela mídia, tendo como referência as celebridades:

A TV, celebridades e tudo mais e tal [influenciam]. Ocê vê elas fazendo aquelas coisa, aí cê fala: 'Ah, vou me inspirar nelas.' $E$ às vezes, você tá tipo mal com você, mas você vê, por exemplo, vô falar de corpo, aí uma pessoa tem o corpo bonito, você se espelha naquela pessoa (O2A3).

Outra influência identificada pelos adolescentes foram os sentimentos presentes no processo de escolha. Ansiedade (O1A1, O1A2, O1A4, O1A7 e O1A8), medo de errar ao escolher (O1A1, O16 e O1A7), dúvida e incerteza (O1A1, O1A2, O1A5, O1A6 e O1A8), estresse (O1A2 e O1A8), aflição e desespero (O1A1 e O1A6) e preocupação (O1A4, O1A5 e O1A6) foram 
sentimentos descritos como presentes no processo de escolha dos(as) adolescentes entrevistados.

A terceira categoria agregou informações que indicaram "onde os(as) adolescentes buscam por saúde e informações de saúde”. Conforme observado, "Todos(as) os(as) adolescentes concordam que a internet é um espaço para ter informações de saúde" (O2). A fala a seguir apresenta a internet como opção de acesso à informação relacionada à saúde: " $E$. . . basicamente na internet mesmo [que podemos buscar informações sobre saúde]" (O2A7). Segundo um dos adolescentes:

Cê pode pesquisar tudo na internet exercício pra fazer. Por exemplo, a pessoa que qué ir na academia, mas não tem dinheiro, ela procura na internet o exercício pra fazer em casa. A pessoa que qué fazer dieta, mas não tem dinheiro pra nutricionista, ai procura na internet uma dieta $(\mathrm{O} 2 \mathrm{Al})$.

Os(as) adolescentes também mencionaram que buscam informações sobre saúde com "pessoas", conforme pode ser observado na fala "Mas onde eu procuro mesmo é sempre nas pessoas, é a minha primeira opção. ... Eu sempre falo com a minha mãe ou com a minha avó" (O2A5), bem como na fala a seguir:

... Eu vou dizer que minha mãe também pode ser minha médica. Ela que cuida de mim, entende? Então, o médico em si seria uma palavra que seria a pessoa que cuida, né, mas não quer dizer que é só o médico profissional, várias pessoas pode cuidar da gente (O2A3).

O "posto de saúde" (O2A5, O2A4 e O2A1) também foi um espaço identificado para a busca de saúde. Embora alguns dos(as) participantes tenham indicado ter acesso à saúde e às informações sobre saúde por meio de equipamentos ou profissionais de saúde, estes aparecem como última opção para alguns. As falas de dois participantes ilustram essa situação. A primeira diz o seguinte: "O médico, pra mim, tá lá embaixo, não procuro médico. Tipo assim, não é uma das minhas primeiras opções. ... Só quando tiver morrendo memo, aí vai pro hospital' (O2A5). Por sua vez, a segunda diz:

Por exemplo, antes, quando eu comecei a fazer academia, as pessoas sempre falam procê: 'Ah cê qué ficar forte, come macarrão, come pão, come esses trem, vai botando tudo pra dentro.' Aí, eu peguei e, antes, eu comia só pão de sal.... Eu ia comendo pão de sal, pão de sal, pão de sal, pão de sal. Eu fui ficano inchado, feio . . . Eu vejo que antes eu me alimentava muito ruim, aí fui ver a nutricionista (O2A3).

\section{Discussão}

A discussão foi organizada em três eixos, que não se atêm necessariamente apenas a uma das categorias apresentadas, mas articulam os pontos convergentes das diferentes categorias.

\section{Eixo 1: adolescências, saúde e seus corpos: rascunho ou potência?}

Considerando o discurso dos(as) adolescentes participantes quando se referem à saúde associada à ausência de doenças, quando se autorresponsabilizam pela própria saúde e quando apontam a busca por saúde/médico apenas quando estão muito doentes, fica evidente que a percepção dos(as) adolescentes sobre suas escolhas em relação à saúde é permeada pelo paradigma biomédico, que qualifica a saúde como ausência de doenças e adota uma lógica unicausal, desconsiderando aspectos da organização política, social e econômica da sociedade humana que também influenciam a saúde (Puttini et al., 2010).

A percepção dos(as) adolescentes deste estudo sobre escolhas relacionadas à saúde assemelha-se aos resultados relatados em outras pesquisas, nos quais se observou que a procura pelos serviços de saúde por adolescentes ocorre a partir de demandas pontuais e urgentes, associadas à busca de cuidados ginecológicos, à gravidez na adolescência e ao uso problemático de álcool e outras drogas (Silva, Matsukura, Ferigato, \& Cid, 2019), ou por causa de urgências/acidentes, pela manifestação de alguma doença (física e psicológica) ou vacinação, sendo o profissional mais procurado o médico (Brito \& Rocha, 2019; Vinagre \& Barros, 2019).

Saúde como felicidade e bem-estar é outra construção discursiva apresentada pelos(as) participantes, resultado também encontrado no estudo de Passos et al. (2013). Evidencia-se novamente, no discurso dos(as) adolescentes, a atribuição única e exclusivamente a si mesmos pela realização de bem-estar/ felicidade, que caberia apenas a eles(as), sem levar em conta todos os atravessamentos sociais, econômicos 
e culturais. A busca por felicidade e bem-estar tem sido cada vez mais pensada como resultado de uma vivência eminentemente pessoal e privada, desconsiderando completamente as origens sociais do sofrimento (Sennett, 1999). Essa forma de perceber a saúde demonstrada pelos(as) adolescentes mostra uma demanda de ações ampliadas das equipes multiprofissionais sobre a discussão dos DSS.

Conforme apontado na categoria "concepções de adolescentes sobre saúde", houve uma construção discursiva de saúde associada à alimentação regrada e à prática de atividade física. Considerando os esforços da PNPS de prever ações voltadas à alimentação saudável e à prática de atividade física (Ministério da Saúde, 2018), foi possível perceber, no discurso dos adolescentes, formas de pensar e produzir saúde alinhadas com tal perspectiva. Além disso, os resultados permitem inferir que, mesmo que de forma incipiente, os(as) adolescentes mostram um progresso ao refletir sobre a saúde, pois não a reconhecem exclusivamente como ausência de doença.

O discurso apresentado pelos(as) participantes desta pesquisa aponta a importância de bons hábitos alimentares e de práticas de atividade física para a saúde. Por outro lado, a Pesquisa Nacional de Saúde do Escolar (PeNSE) demonstrou que, entre adolescentes, os hábitos alimentares e de prática de atividade física se deterioram com o aumento da idade, e que predominaram hábitos alimentares não saudáveis, com alto consumo de açucarados e alimentos processados, associados ao baixo consumo de frutas e verduras (Reis et al., 2018). Isso evidencia a importância de dar continuidade a ações educativas em saúde acerca de tais temáticas.

Os resultados sinalizaram que o cuidado com o corpo também se manifesta quando os(as) adolescentes associam a saúde ao uso de preservativo masculino para a prevenção de IST. Ao pensar sobre o possível uso de preservativos como um indicador de saúde, os adolescentes podem refletir sobre a sexualidade e evidenciam a necessidade de discutir e propiciar educação em saúde sexual e reprodutiva a esse grupo etário, visando a práticas e escolhas saudáveis.

Cercada de tabus, a discussão sobre sexualidade precisa ser ampliada de forma contínua e consistente e realizada por diversos atores de maneira intersetorial, visto que essa discussão permeia a saúde na adolescência (Campos et al., 2017). Faz-se necessário considerar desde o conhecimento sobre o próprio corpo, sobre as relações afetivas e as violências, até aqueles sobre a saúde sexual e reprodutiva. Também é preciso desmistificar os tabus e envolver os/as familiares de maneira a considerar os conhecimentos dos/das adolescentes de forma contextualizada, no sentido da construção de um saber conjunto que rompa com os entraves do desenvolvimento saudável da sexualidade (Ministério da Saúde, 2017; Opas \& Ministério da Saúde, 2017).

O cuidado com o corpo também apareceu no discurso dos(as) participantes quando apontaram que questões estéticas, pautadas nas celebridades/mídia, influenciam suas escolhas em saúde. Nessa direção, os resultados encontrados em uma pesquisa sobre a (in)satisfação com a imagem corporal na adolescência apontaram que as preocupações acerca dos cuidados com o corpo não são uma questão de saúde especificamente, mas de estar ou não satisfeito com o próprio corpo, com base em padrões ideais de beleza impostos socialmente (Marques et al., 2016). A existência de ideais de beleza pode se tornar um problema quando os(as) adolescentes passam a optar por hábitos potencialmente prejudiciais a sua saúde, por não conseguirem atender às exigências dos padrões impostos.

As análises do conteúdo das falas dos participantes permitiram, ainda, destacar o papel determinante da mídia, que atua produzindo e disseminando ideias e formas de ser e estar no mundo. A construção dos discursos midiáticos não raro associa padrões estéticos de beleza do corpo a um estado de saúde, de forma que a mídia converteu-se em "uma instância educativa que define, regula e disciplina corpos, ditando padrões estéticos conforme interesses mercadológicos" (Bittar \& Soares, 2020, p. 301). Ao propagar determinados ideais de beleza, a mídia contribui com a produção de sentimentos de insatisfação com a imagem corporal nos(as) adolescentes.

Encontrou-se no discurso dos(as) adolescentes uma construção da saúde associada à funcionalidade, que deve ser alcançada com muito esforço e sacrifício. Constantemente, vê-se na mídia programas que ensinam como comer, vestir, perder peso e exercitar-se, além de programas que contribuem com uma representação social que dita que o corpo é algo que precisa de constante cuidado e melhoria ou, como propôs Le Breton (2003), como um "atrapalho", um objeto a ser melhorado e superado.

Para Bertolini (2016), essa representação do corpo como algo que precisa ser constantemente cuidado e melhorado inicialmente pode parecer interessante 
e contribuir para o cuidado com a saúde, mas, por outro lado, estaria colaborando, em uma perspectiva foucaultiana, com a produção de corpos economicamente ativos e politicamente dóceis, que se ocupam de si mesmos com vistas a alcançar, a qualquer custo, padrões impostos socialmente, sem questionar a que ou a quem servem tais padrões e sem realizar uma crítica à organização social, política e econômica que contribui com o processo saúde/adoecimento. Isso reforça novamente a necessidade da ampliação da discussão sobre os DSS.

De maneira geral, a percepção dos adolescentes vai ao encontro da "corrente moderna de promoção da saúde", que ainda responsabiliza os indivíduos pelas problemáticas de saúde, em detrimento da "nova promoção de saúde", que compreende a saúde como produção social (Cavalcanti et al., 2015). Tal perspectiva aparentemente tem perpassado o tecido social e produzido subjetividades e formas de pensar a saúde, bem como formas de cuidado da saúde que se traduzem em concepções reducionistas e descontextualizadas.

Assim, ressalta-se a necessidade de diálogo entre adolescentes e os diversos atores sociais que trabalham com esse público. Destaca-se, também, a necessidade de, em uma perspectiva de protagonismo adolescente, construir conjuntamente novas formas de cuidado em saúde pautadas na realidade desse público, considerando suas particularidades. Essas formas devem permitir a ressignificação dos(as) adolescentes sobre seus corpos e auxiliá-los(as) a ultrapassar a autorresponsabilização e a considerar os fatores sociais, econômicos, culturais e ambientais para que o cuidado em saúde possa produzir vida, não sacrifícios e sofrimento.

\section{Eixo 2: adolescências, influências, escolhas e saúde}

Sabe-se que o grupo familiar é o grupo primário de socialização no ciclo vital. Portanto, a família apresenta-se como espaço privilegiado para a elaboração do universo social e para a aquisição de conhecimentos e hábitos (Macedo et al., 2017; Prioste et al., 2019; Ribeiro \& Rocha, 2017). Nesse sentido, é esperado que os adolescentes percebam a família como uma influência para suas escolhas em saúde, o que torna importante que equipes multiprofissionais em saúde reconheçam quais informações e cuidados em saúde a família oferece aos(às) adolescentes.

Outro aspecto importante identificado a partir da literatura é que os(as) adolescentes que enfrentam relações conflituosas com os(as) familiares, que possuem pais com estilos parentais permissivos ou que utilizam uma comunicação violenta têm o desenvolvimento da resiliência impactado de maneira negativa. Em contrapartida, um vínculo familiar de qualidade é fator protetivo e favorece o desenvolvimento saudável da autoestima e autopercepção (Rozemberg et al., 2014). Esses achados apontam para a importância de conhecer os estilos parentais, bem como de favorecer o fortalecimento de vínculos entre família e adolescentes.

Em consonância com os achados deste estudo, Guareschi reconhece que

diferentes práticas engendram objetos sempre diversos, sendo necessário desnaturalizar quaisquer noções totalizantes sobre a infância, adolescência e família que se pretendam permanentes e universais, provocando-se, assim, um contínuo questionamento sobre as relações entre poder e verdade (Guareschi, 2012, p. 266).

Assim, isso significa não incorrer em práticas policialescas e regulatórias, pautadas num ideal único de adolescência e/ou família.

Parece que as fontes de influência das escolhas em saúde desenvolvem-se à medida que os(as) adolescentes adquirem novos interesses, deslocando a família para segundo plano e abrindo espaço para o protagonismo dos grupos de pares. Sabe-se da importância deles para a construção da identidade dos(as) adolescentes, e da necessidade de se sentirem aceitos e pertencentes a um grupo nessa fase da vida (Macedo et al., 2017; Prioste et al., 2019; Ribeiro \& Rocha, 2017). Sabe-se, inclusive, que adolescentes mais aceitos socialmente tendem a apresentar menos problemas de saúde (Veppo et al., 2020). Assim, acompanhando o desenvolvimento psicossocial dos(as) adolescentes, as relações interpessoais apresentam-se como uma influência para a saúde, conforme os(as) participantes sinalizaram.

No entanto, a adolescência não é, no que diz respeito à socialização, ponto inicial ou final. Além disso, há que se considerar que nessa fase da vida ocorrem mudanças significativas na capacidade de pensamento, mais especificamente na capacidade de abstração, o que se soma ao crescente desenvolvimento da autonomia. Dessas novas habilidades e possibilidades emergem novas formas de ver e interpretar o mundo, 
bem como de se relacionar, e, em meio a essas novas relações, os adolescentes adquirem e remodelam comportamentos, valores e atitudes necessários para se adaptarem socialmente (Macedo et al., 2017). Diante dessas considerações, o grupo passa a se apresentar como estratégia privilegiada para que o cuidado com o público adolescente se realize de maneira mais efetiva.

Ao se verem diante de um processo de escolha, os(as) adolescentes relataram que muitos sentimentos desagradáveis afloram, interferindo na forma como tomam suas decisões. Diante desse resultado, é importante destacar que uma das tarefas desenvolvimentais da adolescência é a construção da identidade, que é perpassada por escolhas relacionadas a si mesmo, aos outros e ao futuro, bem como ao desenvolvimento crescente da autonomia (Macedo et al., 2017), o que colocará os(as) adolescentes diante de escolhas constantes, contribuindo para a vivência dos estados emocionais mencionados. Assim, desenvolver práticas que permitam que eles(as) compreendam e manejem suas emoções e sentimentos, bem como compartilhem seus processos de escolha, será fundamental para auxiliá-los(as) a se desenvolverem de modo mais saudável.

Outra influência na saúde apresentada pelos(as) adolescentes foi o uso/abuso de drogas. É importante destacar que há no mundo um crescimento exponencial no contingente de adolescentes que fazem uso/ abuso de drogas, lícitas ou ilícitas, evidenciando um problema de saúde pública, com agravos biopsicossociais (Ribeiro et al., 2018). Reconhecer o uso/abuso de drogas como uma influência negativa na saúde pode ser um primeiro passo para escolhas em saúde mais assertivas, o que torna importante o investimento das equipes multiprofissionais em ações educativas com os(as) adolescentes. Envolver a família em tais ações pode ser um grande diferencial, já que os resultados da PeNSE demonstraram que a supervisão familiar se mostrou protetora quanto ao uso de tabaco, álcool e drogas (Reis et al., 2018). Isso reforça a necessidade de considerar a família nas intervenções com os(as) adolescentes.

Acredita-se que as ações de promoção da saúde para o público adolescente devem priorizar atividades capazes de gerar, a partir do diálogo, reflexão e bem-estar, para além de uma lógica proibicionista, de forma que possam auxiliar na prevenção e desistência da prática do uso ou abuso de substâncias de qualquer espécie. Nesse sentido, criar espaços diferenciados que propiciem construções coletivas é possibilitar que se dê ouvidos às demandas dos(as) adolescentes sobre esse assunto, saciando sua curiosidade, sanando suas dúvidas, aliviando suas angústias e tornando possível promover saúde e proporcionar novos horizontes e perspectivas para que se viva com mais qualidade de vida (Ribeiro et al., 2018).

Outro ponto que mereceu destaque foi a percepção dos(as) adolescentes sobre o trabalho como algo importante na vida do ser humano, bem como fator de risco para a saúde. Os(as) participantes da pesquisa ponderaram que seu excesso pode influenciar a saúde de maneira negativa, considerando que a ação de trabalhar para conquistar estabilidade financeira pode gerar uma baixa qualidade de vida e ocasionar agravos à saúde, como o estresse.

A percepção dos estudantes sobre o impacto do trabalho na saúde é coerente com os estudos sobre estresse ocupacional, que o reconhecem como uma doença crônica recorrente e laboral que pode causar, entre outras consequências, isolamento e afastamento dos familiares, podendo, assim, suprimir ligações afetivas e impedir a criação de novos vínculos, desencadeando outros agravos (Prado, 2016). Esses achados apontam direcionamentos para as equipes multiprofissionais em saúde. Faz-se necessário o aprofundamento de estudos e práticas em saúde do trabalhador com os(as) adolescentes para que eles reconheçam os impactos negativos que certas condições de trabalho causam na saúde e na qualidade de vida de todos(as), permitindo assim que eles possam se prevenir contra esses impactos.

Por fim, no tocante às influências na saúde, a religião foi apresentada como um dos fatores com potencial para influenciar a saúde de maneira positiva. Corroborando essa percepção dos(as) adolescentes, pesquisas científicas têm apresentado estudos específicos sobre os temas "religiosidade", "espiritualidade", "saúde" e "qualidade de vida". Um exemplo é o estudo de Gonçalves, Lucchetti, Leão, Menezes e Vallada (2015), que apresentou práticas e intervenções espirituais e religiosas e concluiu que, na maior parte dos casos, essas práticas causam efeitos benéficos à saúde, podendo reduzir a ansiedade e o estresse dos profissionais da saúde e diminuir a intensidade dos sintomas de depressão e do consumo de drogas. Nesse sentido, as atividades multiprofissionais de promoção de saúde na adolescência devem também considerar as práticas e crenças religiosas dos(as) adolescentes, já que se apresentaram como fator protetivo no cuidado em saúde. 


\section{Eixo 3: adolescências, cultura digital e saúde: articulações possíveis}

Os(as) adolescentes demonstraram buscar saúde em espaços tradicionais, como equipamentos e/ou profissionais de saúde, como última opção. Neste estudo, quanto à procura por informações de cuidado com a saúde, os(as) adolescentes apontaram que fazem uso frequente da internet como canal de informação. Esses achados apresentam elementos que precisam ser considerados pelos profissionais que atuam no cuidado da saúde desse grupo.

O estudo de Vinagre e Barros (2019) pode ser instrumental para a reflexão das equipes multiprofissionais em saúde. Em pesquisa realizada com adolescentes, as autoras identificaram uma avaliação negativa dos serviços de saúde, bem como dos profissionais que os atendem, o que possivelmente ajuda a justificar a procura dos serviços de saúde pelos(as) adolescentes somente em casos de urgência (Vinagre \& Barros, 2019).

Por outro lado, sabe-se que a internet se apresenta como um espaço cada vez mais utilizado no que diz respeito a aspectos relacionados à saúde. Ela figura como a principal fonte de busca por informação sobre saúde, porém, é atribuída baixa credibilidade aos resultados da busca on-line (Moretti et al., 2016). De maneira convergente, a análise de conteúdo das oficinas evidenciou que o principal espaço de procura de informações relacionadas à saúde para esse público é o ciberespaço. Nesse sentido, é preciso considerar que os(as) adolescentes da atualidade cresceram em meio ao uso das redes sociais e dos dispositivos móveis, tecnologias que modelam sua identidade e sua forma de se relacionar com o mundo (Alves, 2017; Bialer \& Voltolini, 2017).

Entretanto, Tiburi (2016) dirá que, nos meios de comunicação em geral, como televisão, rádio e redes sociais, é possível expressar as diferentes formas dos indivíduos e das instituições de pensar o mundo, de maneira livre e sem necessariamente um compromisso ético e legal. Assim, discursos e entendimentos sobre determinados acontecimentos passam a circular e, devido a sua repetição, passam a ser concebidos como verdades, gerando uma nova forma de consumismo: o da linguagem, que, como qualquer consumismo, gera muito lixo. Nessa perspectiva, é preciso uma reflexão profunda acerca desse ciberespaço, na medida em que os(as) adolescentes apontam o acesso a informações confiáveis como uma influência na saúde e que percebemos a internet como um espaço de busca de conhecimento e de esclarecimento de dúvidas sobre as informações recebidas.
Um bom exemplo de prática multiprofissional que utiliza o ciberespaço como ferramenta de educação em saúde para adolescentes é o jogo on-line Papo reto, que tem como objetivo promover conhecimentos em saúde de maneira lúdica e interativa por meio da discussão de temáticas sobre afetos, sexualidade e reprodução. Estudos evidenciaram o grande potencial do jogo para a problematização das vivências relacionadas à saúde sexual e reprodutiva, a partir de uma perspectiva de gênero, possibilitando o protagonismo adolescente e, de maneira crítica e reflexiva, a construção de conhecimentos (Oliveira et al., 2016).

Diante dessas considerações, o ciberespaço se coloca como ambiente pujante para o desenvolvimento de intervenções voltadas ao público adolescente, dada sua familiaridade com as novas tecnologias. Considera-se que pensar as articulações entre adolescências, cultura digital e saúde pode ser um campo pertinente e profícuo de estudos para as equipes multiprofissionais em saúde que desejam melhor compreender e intervir nas adolescências. Contudo, é preciso ir além de uma lógica informativa de transferência de conteúdo, no sentido de pensar estratégias que de fato consigam estabelecer um diálogo com o público-alvo, de forma que o conhecimento possa ser construído de maneira reflexiva, crítica e protagonista.

\section{Considerações finais}

Este estudo teve como objetivo identificar as percepções e escolhas dos(as) adolescentes em relação a sua saúde. A análise do conteúdo das oficinas permitiu detectar diferentes posicionamentos relacionados à saúde, atrelados majoritariamente à perspectiva da corrente moderna de promoção da saúde, que prioriza uma compreensão biomédica e desconsidera os atravessamentos psicossociais que afetam a saúde, evidenciando a necessidade de ampliar a discussão acerca dos DSS com os(as) adolescentes.

Além disso, os(as) adolescentes indicaram como o uso de álcool e drogas e o trabalho podem ser considerados fatores de risco para a saúde. Outra contribuição da pesquisa foi discutir as escolhas e influências em saúde, identificando o papel da família, dos relacionamentos interpessoais, das emoções e da religião nos cuidados em saúde nas adolescências. O estudo também evidenciou o ciberespaço como lócus privilegiado entre adolescentes para a busca de informações sobre saúde, mostrando a importância de levá-lo em consideração na promoção de saúde desse grupo. 
Conclui-se que, em um trabalho multiprofissional para promover a saúde nas adolescências com vistas a um desenvolvimento criativo, potente e libertador, é preciso despir-se de concepções generalistas e ideais de adolescência, sempre considerando a singularidade de cada vivência, sem perder de vista a importância de compreender o espaço/tempo em que se insere cada adolescente, considerando seu contexto, suas crenças e suas percepções de mundo. É preciso também extrapolar os espaços tradicionais de cuidado desse público, já que esses espaços não se apresentam como principal alternativa na busca de cuidado por eles(as). Ir ao encontro dos(as) adolescentes e desenvolver práticas nos locais em que estão inseridos (escolas, praças e ciberespaço, por exemplo) revela-se como alternativa para estudos e intervenções futuras.

Por fim, para além das contribuições, é preciso considerar as limitações que recaem sobre a amostra e o universo da pesquisa, que foi desenvolvida com um pequeno grupo de adolescentes, em um cenário específico e assistida por uma Remsa. No entanto, a partir da perspectiva plural assumida e do caráter qualitativo deste estudo, não se pretendeu realizar generalizações dos resultados de forma a abranger as adolescências como um todo, nem tampouco esgotar o assunto, o que não impede, contudo, que este estudo figure como uma alternativa significativa para a compreensão dos desafios do trabalho das equipes multiprofissionais em saúde no universo das adolescências.

\section{Referências}

Afonso, L. (2006). Oficinas em dinâmica de grupo: Um método de intervenção psicossocial. Casa do Psicólogo.

Alves, M. A. S. (2017). A cibercultura e as transformações em nossas maneiras de ser, pensar e agir. In N. L. Lima, M. Stengel, M. R. Nobre, \&V. C. Dias (Orgs.), Juventude e cultura digital: Diálogos interdisciplinares (pp. 169-180). Artesã.

Bertolini, J. (2016). O corpo na esfera da mídia: Entre representações sociais e biopoder. Ação Midiática, 11, 31-48. http://doi.org/10.5380/2238-0701.2016n1p31-48

Bialer, M., \& Voltolini, R. (2017). Internet e subjetividade contemporânea. In N. L. Lima, M. Stengel, M. R. Nobre, \& V. C. Dias (Orgs.), Juventude e cultura digital: Diálogos interdisciplinares (pp. 57-78). Artesã.

Bittar, C., \& Soares, A. (2020). Mídia e comportamento alimentar na adolescência. Cadernos Brasileiros de Terapia Ocupacional, 28(1), 291-308. https://doi.org/10.4322/2526-8910.ctoar1920

Brito, U. S., \& Rocha, E. M. B. (2019). Percepção de jovens e adolescentes sobre saúde e qualidade de vida. Revista Brasileira de Promoção em Saúde, 32, 1-11. https://doi.org/10.5020/18061230.2019.8933

Campos, H. M., Paiva, C. G. A., Mourthé, I. C. A., Ferreira, Y. F., \& Fonseca, M. C. (2017). Direitos humanos, cidadania sexual e promoção de saúde: Diálogos de saberes entre pesquisadores e adolescentes. Saúde em Debate, 41(113), 658-669. https://doi.org/10.1590/0103-1104201711324

Cavalcanti, P. B., Lucena, C. M. F., \& Lucena, P. L. C. (2015). Programa saúde na escola: Interpelações sobre ações de educação e saúde no Brasil. Textos \& Contextos, 14(2), 387-402. https://doi.org/10.15448/1677-9509.2015.2.21728

Dimenstein, M., Siqueira, K., Macedo, J. P., Leite, J., \& Dantas, C. (2017). Determinação social da saúde mental: Contribuições à psicologia no cuidado territorial. Arquivos Brasileiros de Psicologia, 69(2), 72-87.

Gonçalves, J. P. B., Lucchetti, G., Leão, F. C., Menezes, P. R., \& Vallada, H. (2015). Avaliação da prática de terapia complementar espiritual/religiosa em saúde mental. Revista Debates em Psiquiatria, 6, 21-27.

Guareschi, N. (2012). Infância, adolescência e a família: Práticas PSI, sociedade contemporânea e produção de subjetividade. In A. M. Jacó-Vilela, \& L. Sato (Orgs.), Diálogos em psicologia social (pp. 254-268). Centro Edelstein de Pesquisas Sociais. http://books.scielo.org/id/vfgfh/pdf/jaco-9788579820601-17.pdf

Lane, S. T. M. (2006). O que é psicologia social? (22a ed.). Brasiliense.

Le Breton, D. (2003). Adeus ao corpo. Papirus.

Le Breton, D. (2017). Uma breve história da adolescência. Editora PUC Minas.

Lei n. 8.069, de 13 de julho de 1990. (1990, 16 de junho). Dispõe sobre o Estatuto da Criança e Adolescente e dá outras providências. Diário Oficial da União. http://www.planalto.gov.br/ccivil_03/leis/18069.htm 
Macedo, D. M., Petersen, C. S., \& Koller, S. H. (2017). Desenvolvimento cognitivo, socioemocional e físico na adolescência e as terapias cognitivas contemporâneas. In C. B. Neufeld (Org.), Terapia cognitivo-comportamental para adolescentes: Uma perspectiva transdiagnóstica e desenvolvimental (pp. 25-40). Artmed.

Marques, M. I., Pimenta, J., Reis, S., Ferreira, L. M., Peralta, L., Santos, M. I., Santos, S., \& Santos, E. (2016). (In)satisfação com a imagem corporal na adolescência. Nascer e Crescer, 25(4), 217-221.

Minayo, M. C. S. (Org.), \& Gomes, S. F. D. R. (2009). Pesquisa social: Teoria, método e criatividade (28a ed.). Vozes.

Ministério da Saúde. (2006). Política nacional de promoção da saúde. http://bvsms.saude.gov.br/bvs/publicacoes/ politica_promocao_saude.pdf

Ministério da Saúde. (2010). Diretrizes nacionais para a atenção integral à saúde de adolescentes e jovens na promoção, proteção e recuperação da saúde. https://bvsms.saude.gov.br/bvs/publicacoes/diretrizes_nacionais_atencao_saude_adolescentes_jovens_promocao_saude.pdf

Ministério da Saúde. (2017). Proteger e cuidar da saúde de adolescentes na atenção básica. http:/ /bvsms.saude.gov. $\mathrm{br} / \mathrm{bvs} /$ publicacoes/proteger_cuidar_adolescentes_atencao_basica.pdf

Ministério da Saúde. (2018). Política nacional de promoção da saúde (PNPS): Anexo I da portaria de consolidação $n^{\circ}$ 2, de 28 de setembro de 2017, que consolida as normas sobre as políticas nacionais de saúde do SUS. https://bvsms. saude.gov.br/bvs/publicacoes/politica_nacional_promocao_saude.pdf

Moretti, F. A., Silva, V., \& Barsottini, C. H. (2016, 27-30 de novembro). Comportamento de pacientes em buscas por informação de saúde online e correlações com idade, escolaridade, renda e interação médica [Artigo apresentado]. Anais do XV Congresso Brasileiro de Informática em Saúde, Goiânia, GO, Brasil. http:// docs.bvsalud.org/biblioref/2018/07/906180/anais_cbis_2016_artigos_completos-95-106.pdf

Oliveira, R. N. G., Gessner, R., Souza, V., \& Fonseca, R. M. S. (2016). Limites e possibilidades de um jogo online para a construção de conhecimento de adolescentes sobre a sexualidade. Ciência \& Saúde Coletiva, 21(8), 2383-2392. https:// doi.org/10.1590/1413-81232015218.04572016

Organização Mundial da Saúde. (2011). Declaração política do Rio sobre determinantes sociais da saúde. http:// www.who.int/sdhconference/declaration/Rio_political_declaration_portuguese.pdf

Organização Pan-Americana da Saúde \& Ministério da Saúde. (2017). Saúde e sexualidade de adolescentes. http:// portalarquivos.saude.gov.br/images/PDF/2017/maio/05/LIVRO-SAUDE-ADOLESCENTES.PDF

Oxford Committee for Famine Relief. (2016). Uma economia para 1\%: Como privilégios e poderes exercidos sobre a economia geram situações de desigualdade extrema e como esse quadro pode ser revertido. https://www.oxfam.org/ sites/www.oxfam.org/files/file_attachments/bp210-economy-one-percent-tax-havens-180116-summ-pt.pdf

Passos, M. D., Gugelmin, S. A., Castro, I. R. R., \& Carvalho, M. C. V. S. (2013). Representações sociais do corpo: um estudo com adolescentes do município do Rio de Janeiro, Brasil. Cadernos de Saúde Pública, 29(12), 2383-2393. https:// doi.org/10.1590/0102-311X00027513

Prado, C. E. P. (2016). Estresse ocupacional: Causas e consequências. Revista Brasileira de Medicina, 14(3), 285-289. https://doi.org/10.5327/Z1679-443520163515

Prioste, A., Tavares, P., \& Magalhães, E. (2019). Tipologias de funcionamento familiar: Do desenvolvimento identitário à perturbação emocional na adolescência e adultez emergente. Análise Psicológica, 37(2), 173-192. https:// doi.org/10.14417/ap.1534

Puttini, R. F., Pereira Junior, A., \& Oliveira, L. R. (2010). Modelos explicativos em saúde coletiva: Abordagem biopsicossocial e auto-organização. Physis: Revista de Saúde Coletiva, 20(3), 753-767.

Reis, A. A. C., Malta, D. C., \& Furtado, L. A. C. (2018). Desafios para as políticas públicas voltadas à adolescência e juventude a partir da Pesquisa Nacional de Saúde do Escolar (PeNSE). Ciência \& Saúde Coletiva, 23(9), 2879-2890. https:// doi.org/10.1590/1413-81232018239.14432018

Ribeiro, C. A., \& Rocha, F. N. (2017). Escolhas na adolescência: Implicações contemporâneas dos grupos sociais e da família. Revista Mosaico, 8(2), 39-47. https://doi.org/10.21727/rm.v8i2.1111

Ribeiro, W. A., Andrade, M., Cirino, H. P., Teixeira, J. M., Martins, L. M., \& Mariano, E. S. (2018). Adolescência, tabaco, álcool e drogas: Uma revisão no olhar preventivo da educação em saúde na ESF. Revista Pró-UniverSUS, 9(1), 2-6.

Rozemberg, L., Avanci, J., Schenker, M., \& Pires, T. (2014). Resiliência, gênero e família na adolescência. Ciência \& Saúde Coletiva, 19(3), 673-684. https://doi.org/10.1590/1413-81232014193.21902013

Sennett, R. (1999). O declínio do homem público: As tiranias da intimidade. Companhia das Letras. 
Silva, J. F., Matsukura, T. S., Ferigato, S. H., \& Cid, M. F. B. (2019). Adolescência e saúde mental: A perspectiva de profissionais da Atenção Básica em Saúde. Interface: Comunicação, Saúde, Educação, 23, 1-14. https://doi.org/ $10.1590 /$ interface. 180630

Souza, C., \& Silva, D. N. H. (2018). Adolescência em debate: Contribuições teóricas à luz da perspectiva histórico-cultural. Psicologia em Estudo, 23, 23-34. https://doi.org/10.4025/psicolestud.v23i0.35751

Spink, M., Menegon V. M., \& Medrado, B. (2014). Oficinas como estratégias de pesquisa: Articulações teórico-metodológicas e aplicações ético-políticas. Revista Psicologia e Sociedade, 26(1), 32-43. https://doi.org/10.1590/ S0102-71822014000100005

Tiburi, M. (2016). Como conversar com um fascista: Reflexões sobre o cotidiano autoritário brasileiro (6a ed.). Record.

Veppo, F., Perpétuo, C., Ribeiro, O., \&Veríssimo, M. (2020). Aceitação social e comportamentos de saúde: a vinculação como variável moderadora. Psicologia, Saúde \& Doenças, 21(1), 38-44. https://doi.org/10.15309/20psd210107

Vinagre, M. G., \& Barros, L. (2019). Preferências dos adolescentes sobre os cuidados de saúde. Ciência \& Saúde Coletiva, 24(5), 1627-1636. https:// doi.org/10.1590/1413-81232018245.04362019

Vinuto, J. (2014). A amostragem em bola de neve na pesquisa qualitativa: Um debate em aberto. Temáticas, 22(44), 203-220. https://doi.org/10.20396/tematicas.v22i44.10977

\section{Débora Silveira Duarte}

Psicóloga Especialista em Saúde do Adolescente. Especialista em Saúde do Adolescente pela Universidade Federal de São João del-Rei (UFSJ), Divinópolis - MG. Brasil.

E-mail: deborasd18@hotmail.com

(D) https://orcid.org/0000-0002-0099-5808

\section{Lilian Fernanda Silva}

Assistente Social Especialista em Saúde do Adolescente pela Universidade Federal de São João del-Rei (UFSJ),

Divinópolis - MG. Brasil.

E-mail: lilianfs2019@gmail.com

(iD https://orcid.org/0000-0003-1411-348X

\section{Virgínia Junqueira Oliveira}

Professora da Universidade Federal de São João del-Rei Campus Centro Oeste (UFSJ), Divinópolis - MG. Brasil.

E-mail: viju.oli@gmail.com

(iD) https://orcid.org/0000-0003-1151-7673

\section{Patrícia Pinto Braga}

Professora da Universidade Federal de São João del-Rei Campus Centro Oeste (UFSJ), Divinópolis - MG. Brasil.

E-mail: patriciabragaufsj@gmail.com

iD https://orcid.org/0000-0002-1756-9186

Endereço para envio de correspondência:

Universidade Federal de São João del-Rei, Campus Centro Oeste. Rua Sebastião Gonçalves Coelho, 400,

Chanadour. CEP: 35501-296. Divinópolis - MG. Brasil.

Recebido 30/01/2019

Aceito $11 / 11 / 2020$

Received $01 / 30 / 2019$

Approved 11/11/2020 
Recibido 30/01/2019

Aceptado 11/11/2020

Como citar: Duarte, D. S., Silva, L. F., Oliveira, V. J., \& Braga, P. P. (2021). Percepções e escolhas de adolescentes sobre saúde no contexto da residência multiprofissional. Psicologia: Ciência e Profissão, 41, 1-17.

https://doi.org/10.1590/1982-3703003219264

How to cite: Duarte, D. S., Silva, L. F., Oliveira, V. J., \& Braga, P. P. (2021). Health perceptions and choices of adolescents in a multidisciplinary residency context. Psicologia: Ciência e Profissão, 41, 1-17.

https://doi.org/10.1590/1982-3703003219264

Cómo citar: Duarte, D. S., Silva, L. F., Oliveira, V. J., \& Braga, P. P. (2021). Percepciones y elecciones de adolescentes sobre salud en el contexto de la residencia multiprofesional. Psicologia: Ciência e Profissão, 41, 1-17.

https://doi.org/10.1590/1982-3703003219264 